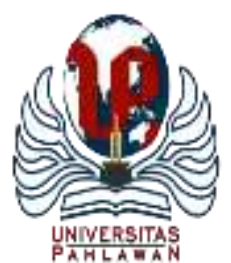

Edukatif : Jurnal Ilmu Pendidikan Volume 4 Nomor 1 Tahun 2022 Halm 803 - 814 EDUKATIF: JURNAL ILMU PENDIDIKAN

Research \& Learning in Education

https:/ledukatif.org/index.php/edukatif/index

\title{
Analisis Framing dan Diksi Berita pada Media Online Detik Travel dan CNN Indonesia Sebagai Bahan Ajar Teks Berita
}

\author{
Citra Retno Yulianti ${ }^{1 凶}$, Hendra Setiawan ${ }^{2}$ \\ Universitas Singaperbangsa Karawang, Indonesia ${ }^{1,2}$

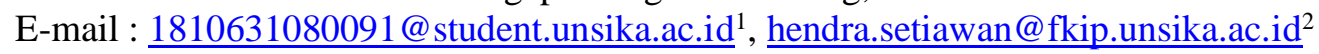

\begin{abstract}
Abstrak
Adanya pembangunan ulang Taman Nasional Komodo, membuat masyarakat geram kepada KLHK atau Kementerian Lingkungan Hidup dan Kehutanan Republik Indonesia dan tepat pada bulan September 2021 staf KLHK tertangkap mengamuk saat pelaksanaan webinar. Berbagai media online pun menyoroti kasus ini, sehingga peneliti tertarik untuk mengetahui bagaimana pengemasan framing, cara kerja framing pada masing-masing media online serta untuk mengetahui pemilihan diksi dalam teks berita. Adapun metode penelitian yang digunakan adalah metode kualitatif dengan model analisis framing Zhong Dang Pan dan Gerald M. Kosicki. Perbedaan pengemasan framing dapat terlihat jelas utamanya pada judul berita. DetikTravel menyisipkan kalimat "Memangnya Kami Penjahat?" pada judul sementara pada CNN Indonesia terdapat kalimat "Kami Bukan Penjahat!”. Preposisi dalam analisis struktur tematik, turut menunjukkan detail perbedaan yang jelas, dimana pada DetikTravel hanya menuliskan mengenai keributan sedangkan CNN Indonesia menjelaskan kronologi keributan. Adapun dalam pemilihan diksi keduanya sama-sama menggunakan beragam diksi dalam penulisan berita. Mulai dari kata baper, berang, nada tinggi hingga terdapat idiom kebakaran janggut. Tentu pengemasan framing serta pemilihan diksi dari DetikTravel dan CNN Indonesia sangat bermanfaat sebagai bahan ajar di SMP, terutama pada materi teks berita sehingga siswa mudah memahami materi secara keseluruhan dan pembelajaran lebih efektif dan variatif.
\end{abstract}

Kata Kunci: Analisis Framing, Diksi, Berita, Media Online, Bahan Ajar.

\begin{abstract}
The redevelopment of the Komodo National Park made people angry with the KLHK or the Ministry of Environment and Forestry of the Republic of Indonesia and precisely in September 2021 KLHK staff were caught raging during the webinar. Various online media have also highlighted this case, so that researchers are interested in knowing how framing is packaged, how framing works in each online media and to determine the choice of diction in news texts. The research method used is a qualitative method with a framing analysis model of Zhong Dang Pan and Gerald M. Kosicki. The difference in framing packaging can be seen clearly, especially in the news title. DetikTravel inserts the sentence "Are we really criminals?" in the provisional title on CNN Indonesia there is the sentence "We are not criminals!". Prepositions in the thematic structure analysis, also show clear details of differences, where in DetikTravel only writes about the commotion while CNN Indonesia explains the chronology of the commotion. As for the choice of diction, both are equally using various dictions in writing news. Starting from baper, angry, high-pitched words to the idiom of beard fire. Of course the framing packaging and the selection of diction from DetikTravel and CNN Indonesia are very useful as teaching materials in junior high school, especially on news text material so that students can easily understand overall material and learning is more effective and varied.
\end{abstract}

Keywords: Framing Analysis, Diction, News, Online Media, Teaching Materials

Copyright (c) 2022 Citra Retno Yulianti, Hendra Setiawan

$\square$ Corresponding author

Email : $1810631080091 @$ student.unsika.ac.id

DOI : https://doi.org/10.31004/edukatif.v4i1.1859

ISSN 2656-8063 (Media Cetak)

ISSN 2656-8071 (Media Online)

Edukatif : Jurnal Ilmu Pendidikan Vol 4 No 1 Tahun 2022

p-ISSN 2656-8063 e-ISSN 2656-8071 


\section{PENDAHULUAN}

Tepat pada tahun 2020 di tengah tingginya kasus Covid-19 di Indonesia. Pemerintah melakukan pembangunan ulang Taman Nasional Komodo yang berada di Kabupaten Manggarai Barat, Nusa Tenggara Timur. Pembangunan dilakukan secara besaran-besaran dengan menggunakan berbagai alat berat. Pembangunan tersebut dinamakan "Proyek Jurassic Park". Adapun proyek tersebut sudah direncakan sejak lama sebelum Presiden Joko Widodo memimpin. Namun, pembangunan tersebut baru dimulai setelah mendapatkan izin lingkungan hidup pada 4 September 2020 mengenai kegiatan Penataan Kembali Kawasan Pulau Rinca di Desa Pasir Panjang, Kecamatan Komodo Kabupaten Manggarai Barat.

Proyek penataan Taman Nasional Komodo disebut-sebut mengeluarkan anggaran kurang lebih Rp.21,25 miliar untuk sarana dan prasarana, Rp.2,41 miliar untuk reservoir SPAM, serta pembangunan pengamanan pantai Lohbuaya sebesar Rp.46,3 miliar (Kementerian PUPR)(Wijaya, 2020). Tentu jumlah tersebut sangat besar, terlebih lagi pandemi masih terus melanda Indonesia dan dampak risiko yang di timbulkan tentu akan menimbulkan kerugian. Sejalan dengan pembangunan proyek Taman Nasional Komodo, berbagai penolakan atas proyek tersebut muncul. Mulai dari penduduk asli hingga Unesco pun mentang proyek Jurassic Park ini. Hingga tagar \#savekomodo turut menjadi topik terpopuler di aplikasi Twitter sebagai bentuk penolakan masyarakat Indonesia.

Adapun penolakan-penolakan tersebut muncul setelah beredar foto di media sosial, seekor komodo yang menghalau truk proyek. Akhirnya hal tersebut, memancing amarah masyarakat dan menganggap proyek Jurassic Park akan merusak habitat asli komodo, mengusir penduduk asli dan hanya mementingkan keuntungan para pejabat yang berinvestasi. Oleh sebab itu bermula dari risiko-risiko yang terjadi, seharusnya dapat dipikirkan kembali secara matang agar tidak merugikan masyarakat serta hewan-hewan habitat asli Taman Nasional Komodo. Perencanaan, pematangan serta kebijakan proyek sangat diperlukan dalam pembangunan proyek. Selain itu edukasi dan keterbukaan terkait proyek harus dipaparkan kepada masyarakat, agar tidak lagi terjadi boikot atau pertentangan terhadap proyek. Untuk itu, perlu adanya peran media massa kompeten yang mampu memberikan edukasi dan informasi kepada masyarakat terkait proyek-proyek yang sedang dijalankan dan direncanakan oleh pemerintah, agar kasus serupa seperti pertentangan dalam proyek Jurassic Park tidak terjadi kembali.

Media massa yaitu suatu sarana informasi, yang bertujuan untuk memenuhi kebutuhan informasi dan hiburan masyarakat. Dalam jurnalistik, media massa dapat dikatakan dengan istilah pers yang berperan untuk menyiarkan suatu berita atau informasi. Adapun menurut Undang Undang pokok pers pasal 1 ayat (1) bahwa pers merupakan lembaga sosial serta alat komunikasi massa yang melakukan aktivitas semacam mencari, mendapatkan, memiliki, menyimpan, mengelola, serta mengantarkan berupa tulisan, suara, foto, grafik, maupun yang lainnya pada media elektronik atau cetak (Widarmanto, 2017, hal. 9-10).

Media massa umumnya dibagi menjadi dua jenis yaitu media cetak dan media elektronik. Media cetak merupakan salah satu media massa pertama dengan perkembangan teknologi yang belum berkembang. Media cetak menyajikan berita dalam bentuk tulisan. Media cetak terdiri dari surat kabar harian, surat kabar. Sedangkan media online merupakan suatu sarana informasi yang cara penyebarannya dengan memanfaatkan koneksi internet. Adapun dalam penulisan berita pada suatu media, perlu adanya bahasa tulisan yang berperan sebagai alat komunikasi, mampu menuangkan gagasan dalam bentuk tulisan sehingga komunikasi tidak langsung dapat terjaga dan informasi serta gagasan dapat tersampaikan dengan baik (Tarigan, 2013).

Media online menyebarkan informasi dengan menggunakan perangkat komputer dan smartphone yang dilengkapi dengan jaringan internet. Media online berkembang dengan sangat canggih dan mampu menarik banyak sekali perhatian. Hampir setengah penduduk di dunia menggunakan media internet sebagai alat untuk mengakses berbagai informasi dari media online (Suryawati, 2014, hal. 46-49). Kelebihan media online dibandingkan dengan media lainnya adalah dalam penyebaran berita, media online mampu menjelajah dimana 
dan kapan saja dengan syarat terhubung pada suatu koneksi internet (Fadilah et al., 2020). Namun media online seringkali menimbulkan opini serta dampak negatif yang beragam (Setiawan \& Nulhakim, 2019). Oleh sebab itu dalam penulisan media online harus jelas agar informasi yang disampaikan jelas dan tidak megalami multitafsir. Hal positif dari media online adalah mampu menyebarkan informasi secara cepat karna proses penyajian informasinya singkat dan sederhana.

Media online tidak memiliki keterbatasan dimensi ruang dan waktu sehingga dapat dijangkau dimana saja dan hal tersebutlah yang menjadi daya tariknya sebagai sebuah media informasi (Nilamsari et al., 2016). Dalam hal ini, setiap media memiliki gaya dan ciri khas masing-masing dalam menulis suatu berita, meskipun saling berkaitan dengan pokok bahasan atau peristiwa yang sama. Sebab suatu peristiwa yang sama dapat diperlakukan secara berbeda oleh media. Beberapa peristiwa ada yang dilaporkan, ada yang tidak dilaporkan, ada beberapa aspek yang disorot, dan ada yang dihilangkan. Aspek-aspek penulisan merupakan konsep yang dasarframing.

Framing adalah salah satu cara untuk menyajikan suatu peristiwa dengan menekankan bagian tertentu, menonjolkan aspek tertentu, dan membesarkan cerita atau informasi tertentu dari suatu realitas atau peristiwa sehingga mudah diingat oleh khalayak (Eriyanto, 2011, hal. 11). Dalam menyajikan framing, sorang penulis/wartawan harus pandai dalam memilih kata (diksi) yang akan dituangkannya pada saat penulisan berita. Pemilihan kata atau diksi merupakan suatu upaya menyeleksi kata-kata tertentu yang akan digunakan dalam ujaran. Adapun sebuah kata dipilih ketika terdapat beberapa kata yang memiliki arti yang serupa atau mirip. Dalam analisis framing terdapat berbagai model yang dikembangkan oleh berbagai ahli antara lain model Robert N. Entman, William A. Gamson, M. Edelman dan Zhong Dang Pan dan M. Kosicki yang masing masing model framingnya memiliki struktur atau perangkat framing yang berbeda (Suprobo et al., 2016).

Pemilihan diksi turut didasari oleh ketepatan dan kecocokan. Dalam hal ini penggunaan diksi umumnya ditujukan untuk mempertayakan kemampuan berdiksi dalam upaya menghasilkan ide atau gagasan yang tepat di benak pembaca (masyarakat umum), sebagaimana yang dimaksudkan oleh penulis (Ramdoni et al., 2021). Ketepatan kata dan pemilihan kata (diksi) dalam penulisan framing berita berkaitan dengan pemaknaan kosakata setiap pembacanya. Ketepatan pemaknaan dalam hal ini untuk menghubungkan kata agar akurat dan memiliki perluasa makna kata, sehingga pemikiran penulis dapat tersampaikan.

Adapun media online yang menjadi subjek dalam penelitian adalah DetikTravel dan CNN Indonesia. DetikTravel merupakan salah satu bagian dari situs berita atau media online yang dibuat oleh PT Agranet Multicitra Siberkom (Agrakom). Detik lahir pada 9 Juli 1998 dengan judul berita pertama mengenai Munas Golkar ditulis oleh Budi Darsono. Saat ini detik.com menjadi situs berita online Indonesia yang menyampaikan mengenai berita politik, ekonomi, teknologi informasi, destinasi wisata, kesehatan. Sementara CNN Indonesia merupakan portal berita milik Trans Media, yang tayangan perdana pada senin 17 Agustus 2015 dengan membawa visi misi mengungkapkan fakta secara apa adanya dan membilasnya dari bias.

Penelitian ini bertujuan untuk melihat pembingkaian media online dalam menjabarkan dan mengemas sebuah berita. Serta untuk menganalisis keragaman diksi dalam penulisan berita di media online. Seperti yang diketahui diksi dimaknai sebagai penggunaan kata yang bertujuan untuk menyusun kalimat yang tepat dan menarik (Fajriyani et al., 2020). Adapun analisis framing dalam penelitian ini menggunakan model analisis yang dikembangkan oleh Zhong Dang Pan dan Gerald M. Kosicki, karna model yang dikembangkan sangat detail dalam melihat sebuah pembingkaian berita. Zhong Dang Pan Dan Gerald M. Kosicki d membagi struktur teks berita sebagai perangkat framing ke dalam empat dimensi struktural yaitu sintaksis, skrip, tematik dan retoris.

Struktur Sintaksis dapat dilihat dari bagan berita. Sintaksis berhubungan dengan bagaimana wartawan menyusun suatu peristiwa, menjadi sebuah berita. Bentuk sintaksis yang paling umum adalah pramida terbalik yang dimulai dengan judul headline, lead, episode, setting dan ending. Dalam bentuk ini bagian yang di atas 
ditampilkan lebih penting dibanding bagian bawah.

Struktur Skrip melihat bagaimana wartawan mengemas suatu peristiwa. Di dalam struktur skrip kemasan suatu berita dapat berisikan hubungan antara peristiwa satu dengan sebelumnya, atau untuk penghubung teks yang ditulis dengan lingkungan komunal pembaca. Secara umum bentuk struktur skrip ini adalah $5 \mathrm{~W}+1 \mathrm{H}$, Who, What, When, Where, Why dan How.

Struktur Tematik yaitu cara pandang seorang wartawan atas suatu peristiwa kedalam proposisi, kalimat, atau hubungan antar kalimat yang membentuk teks. Struktur tematik berhubungan dengan fakta yang ditulis dalam suatu berita. Struktur Retoris berhubungan dengan cara wartawan menekankan arti tertentu yang digambarkan dari pilihan gaya atau kata. Unsur-unsur struktur retorika meliputi leksikon, pemilihan dan penggunaan kata-kata untuk menandai atau menggambarkan peristiwa. Selain penekanan pada kata-kata, penekanan dapat dilakukan melalui grafik berupa gambar, tabel, foto, dll.

Adapun penelitian sebelumnya pernah dikaji oleh Resti Rismayanti pada tahun 2020 dengan judul "Framing Berita Perundungan dalam Pemberitaan Media Elektronik sebagai Bahan Ajar Teks Berita untuk Siswa SMP (Analisis Framing Model Robert N. Entman)". Penelitian ini menunjukkan bahwa teks berita perundungan dari media elektronik (online) dapat digunakan sebagai bahan untuk siswa SMP.

Penelitian serupa juga dilakukan oleh Hendra Setiawan pada tahun 2019 dengan judul Analisis Framing Zong Dang Pan dan Gerald M. Kosicki pada Pemberitaan Kasus Dugaan Ujaran Kebencian Habib Bahar Bin Smith kepada Presiden Joko Widodo (Studi Kasus pada Kompas.com Edisi 3 Desember 2018). Dalam penelitian tersebut menunjukkan bahwa model analisis framing Zong Dang Pan dan Gerald M. Kosicki yang mampu menunjukkan hasil framing berita secara detail.

Sedangkan peneliti memilih untuk menganalisis framing dan diksi berita ngamuknya staf KLHK saat webinar pada media online DetikTravel dan CNN Indonesia sebagai bahan ajar teks berita yang diharapkan dapat membuka pemahaman baru mengenai isi berita secara realistis, jelas dan tepat. Analisis framing ini secara khusus dapat dimanfaatkan sebagai bahan ajar utamanya bagi siswa SMP, karena teori framing selaras dengan teori teks berita yang turut tercantum dalam kurikulum KI dan KD 3.1 dan 4.1. mengenai struktur skrip yang menganalisis unsur-unsur teks berita dalam bentuk $(5 \mathrm{~W}+1 \mathrm{H})$. Serta kebaruan antara analisis framing dan diksi dalam berita ini diharapkan mampu menambah keragaman serta pemahaman mengenai diksi (kata) untuk masyarakat.

\section{METODE PENELITIAN}

Metode yang digunakan dalam penelitian ini adalah metode kualitatif. (Sugiyono, 2015) mengemukakan metode penelitian kualitatif merupakan metode penelitian baru yang didasari oleh filsafat positivisme, yang melihat pada realitas atau fenomena yang diklasisfikasikan konkrit, terukur dan memiliki hubungan sebab akibat. Metode penelitian kualitatif juga dinamakan sebagai metode postposiyivistik karena berlandaskan pada filsafat postpositivisme. Dalam melakukan penelitian dengan metode kualitatif, peneliti melakukan dengan kondisi alamiah, dengan perkembangan objek yang apa adanya dan peneliti berperan sebagai human instrument. Analisi framing dan diksi ini juga menggunakan penelitian yang bersifat deskriptif. Penelitian deskriptif yaitu memaparkan seluruh gejala, peristiwa penelitian dari berbagai fenomena komunikasi yang terjadi (Prasetyo et al., 2020).

Adapun penelitian mengenai analisis framing berita yang didasai oleh teori framing Zhong Dang Pan dan Gerald M. Kociski yang menyatakan bahwa framing berita adalah suatu proses penyampaian/pembuatan pesan dengan isi yang lebih menonjol atau menempatkan informasi lebih daripada yang lain sehingga khalayak lebih tertuju serta tertarik pada pesan tersebut (Eriyanto, 2011, hal. 11). Peneliti menggunakan model Zhong Dang Pan dan Gerald M. Kociski karena terdapat 4 elemen pembentuk suatu berita yang saling berhubungan dalam susunan pemberitaannya antaralain yaitu sintaksis, skrip, tematik, dan retoris. Analisis 
framing model Zhong Dang Pan dan Gerald M. Kociski seringkali digunakan dalam penelitian sebab model ini merupakan model analisis framing yang detail untuk menganalisis pembingkaian berita (Harnia et al., 2021).

Mengenai teknik pengumpulan data, peneliti melakukan pengumpulan informasi dari berbagai sumber yang berkaitan dengan permasalahan penelitian utamanya adalah di media online DetikTravel dan CNN Indonesia selanjutnya menyimak penggunaan kosa kata yang digunakan pada media online. Kemudian teknik analisis data, peneliti melakukannya dengan cara membaca serta menandai gagasan penting setelah itu, menganalisis dan mendeskripsikan dengan menggunakan framing Zhongdang Pan dan Gerald M. Kosicki hingga tahap akhir adalah penarikan kesimpulan kedalam bentuk paparan hasil analisis.

Berikut adalah tabel data berita kasus Staf KLHK Ngamuk saat Webinar Terkait Komodo pada media online DetikTravel dan CNN Indonesia.

Tabel 1 Data Berita yang Diteliti

\begin{tabular}{cccc}
\hline No & $\begin{array}{c}\text { Nama Media } \\
\text { Online }\end{array}$ & Waktu Terbit & Judul Berita \\
\hline 1 & $\begin{array}{c}\text { DetikTravel } \\
\text { (Khoiri, 2021) }\end{array}$ & $\begin{array}{c}\text { Kamis, 16 } \\
\text { September 2021 }\end{array}$ & $\begin{array}{c}\text { Staf KLHK } \\
\text { Ngamuk di } \\
\text { Webinar Komodo, } \\
\text { Memangnya Kami } \\
\text { Penjahat? }\end{array}$ \\
\hline 2 & CNN Indonesia & Kamis, 16 & $\begin{array}{c}\text { Staf KLHK } \\
\text { (Lingga, 2021) }\end{array}$ \\
& & September 2021 & $\begin{array}{c}\text { Webinar: Kami } \\
\text { Bukan Penjahat! }\end{array}$ \\
\hline
\end{tabular}

\section{HASIL DAN PEMBAHASAN PENELITIAN}

Analisis penelitian ini bertujuan untuk mengetahui bagaimana framing yang terdapat dalam pemberitaan media DetikTravel dan CNN Indonesia bekerja. Dalam hal ini, media online dimaknai sebagai suatu sarana komunikasi online (Romli \& Kurniawan, 2012, hal. 32). Untuk itu media online umumnya rentan sebagai media penggiring opini masyarakat karena jangkauannya yang luas dan cepat. Dalam hal ini suatu informasi dapat diketahui secara jelas dan menarik, bergantung pada pengemasan framing di dalamnya. Dampak dasar adanya framing adalah realitas sosial yang kompleks dan tidak beraturan kemudian dapat disajikan dalam berita dengan bentuk yang sederhana, beraturan dan memenuhi logika (Marzuki \& Kahar, 2016).

Framing yang terdapat dalam berita secara khusus dapat bermanfaat sebagai bahan ajar untuk siswa. Bahan ajar sendiri, merupakan gabungan materi pelajaran yang disusun secara sistematis dengan berbagai konsep yang bertujuan untuk mencapai standar kompetensi siswa (Magdalena et al., 2020). Adapun tema berita yang diamati yaitu mengenai kasus staf dari Kementerian Lingkungan Hidup dan Kehutanan (KLHK) yang ngamuk saat webinar. Analisis dilakukan dengan menggunakan model analisis Zhong Dang Pan dan Gerald M. Kociski yang terdiri atas empat struktur pembentuk yaitu struktur sintaksis, skrip, tematik, serta retoris. Peneliti menganalisis menggunakan skema berikut untuk memudahkan pembaca dalam memahami analisis framing dan diksi berita dengan model analisis Zhong Dang Pan dan Gerald M. Kociski. 
808 Analisis Framing dan Diksi Berita pada Media Online Detik Travel dan CNN Indonesia Sebagai Bahan Ajar Teks Berita - Citra Retno Yulianti, Hendra Setiawan

DOI: https://doi.org/10.31004/edukatif.v4i1.1859

Tabel 2 Skema Analisis Pemberitaan Detiktravel dan CNN Indonesia Pada Kasus Staf KLHK yang Mengamuk Saat Webinar

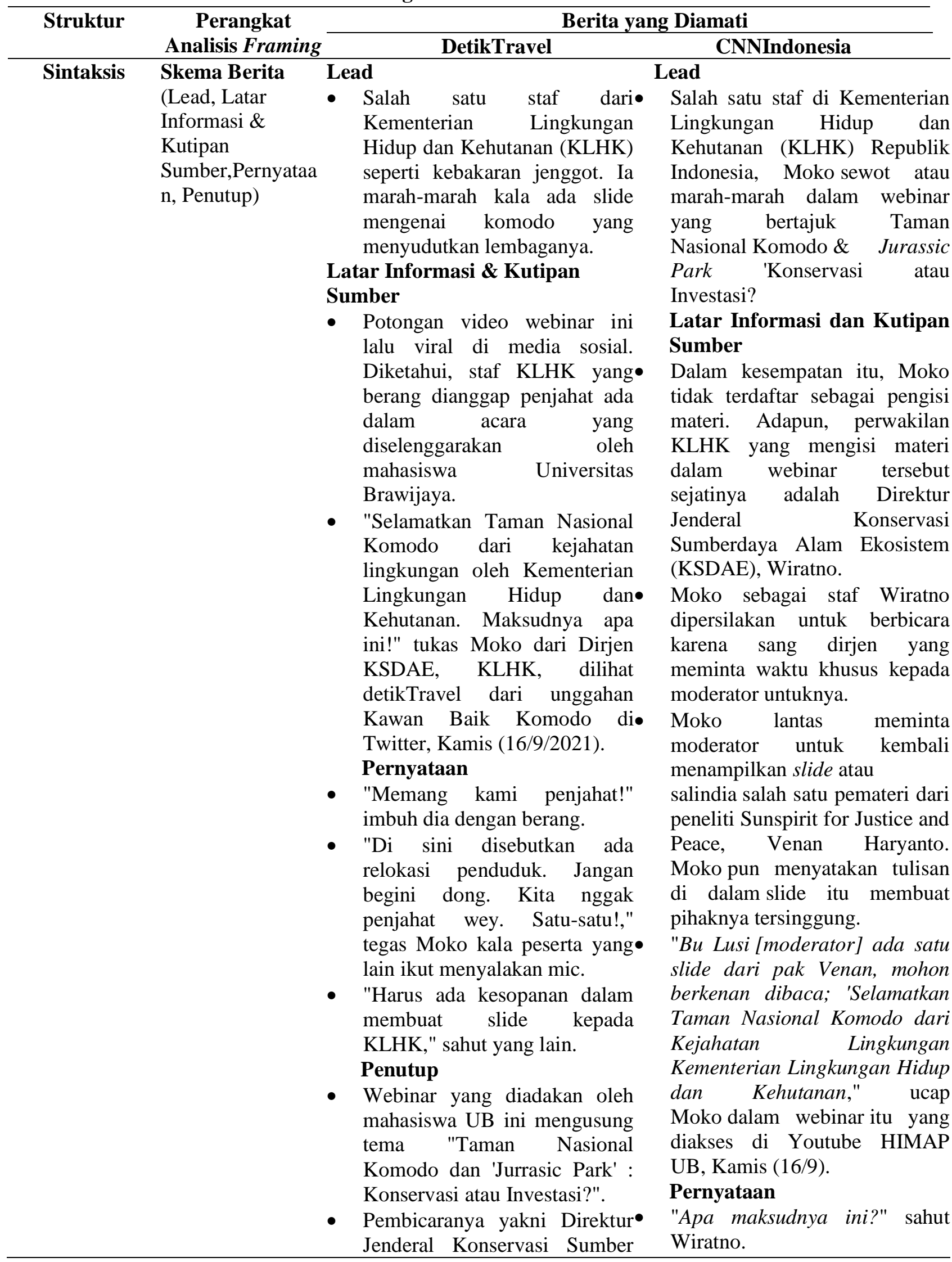


809 Analisis Framing dan Diksi Berita pada Media Online Detik Travel dan CNN Indonesia Sebagai Bahan Ajar Teks Berita - Citra Retno Yulianti, Hendra Setiawan

DOI: https://doi.org/10.31004/edukatif.v4i1.1859

\begin{tabular}{|c|c|c|c|}
\hline \multirow[t]{3}{*}{ Struktur } & \multirow{2}{*}{$\begin{array}{c}\text { Perangkat } \\
\text { Analisis Framing }\end{array}$} & \multicolumn{2}{|c|}{ Berita yang Diamati } \\
\hline & & DetikTravel & CNNIndonesia \\
\hline & & $\begin{array}{l}\text { Daya Alam dan Ekosistem• } \\
\text { (KSDAE), Wiratno, Direktur } \\
\text { Utama Badan Pelaksana } \\
\text { Otorita Labuan Bajo Flores) } \\
\text { Shana Fatina Sukarsono, } \\
\text { Kepala Dinas Pariwisata dan } \\
\text { Ekonomi Kreatif (Parekraf) } \\
\text { NTT, Zet Sony Libing, Kepala } \\
\text { Divisi Sumber Daya Alam• } \\
\text { WALHI NTT, Yuvensius } \\
\text { Nonga, dan Peneliti Sunspirit } \\
\text { for Justice and Peace, Venan } \\
\text { Haryanto. }\end{array}$ & $\begin{array}{l}\text { "Memang kami penjahat? Kami } \\
\text { bukan penjahat } \\
\text { wey!" sambung Moko dengan } \\
\text { nada tinggi. } \\
\text { "Harus ada kesopanan dalam } \\
\text { membuat slide kepada } \\
\text { KLHK!" tegasnya. } \\
\text { Penutup } \\
\text { Diketahui, UNESCO meminta } \\
\text { pemerintah Indonesia } \\
\text { menghentikan sementara semua } \\
\text { proyek infrastruktur di dalam } \\
\text { dan sekitar Taman Nasional } \\
\text { Komodo yang berpotensi } \\
\text { berdampak pada nilai universal } \\
\text { luar biasa atau Outstanding } \\
\text { Universal Value (OUV). }\end{array}$ \\
\hline
\end{tabular}

$\begin{array}{lll}\text { Kkrip } \begin{array}{l}\text { Kelengkapan } \\ \text { Berita }\end{array} & \begin{array}{l}\text { What (Apa peristiwa yang } \\ \text { terjadi?) }\end{array} \text { What (Apa peristiwa yang } \\ \text { terjadi?) }\end{array}$



Ajar Teks Berita - Citra Retno Yulianti, Hendra Setiawan

DOI: https://doi.org/10.31004/edukatif.v4i1.1859

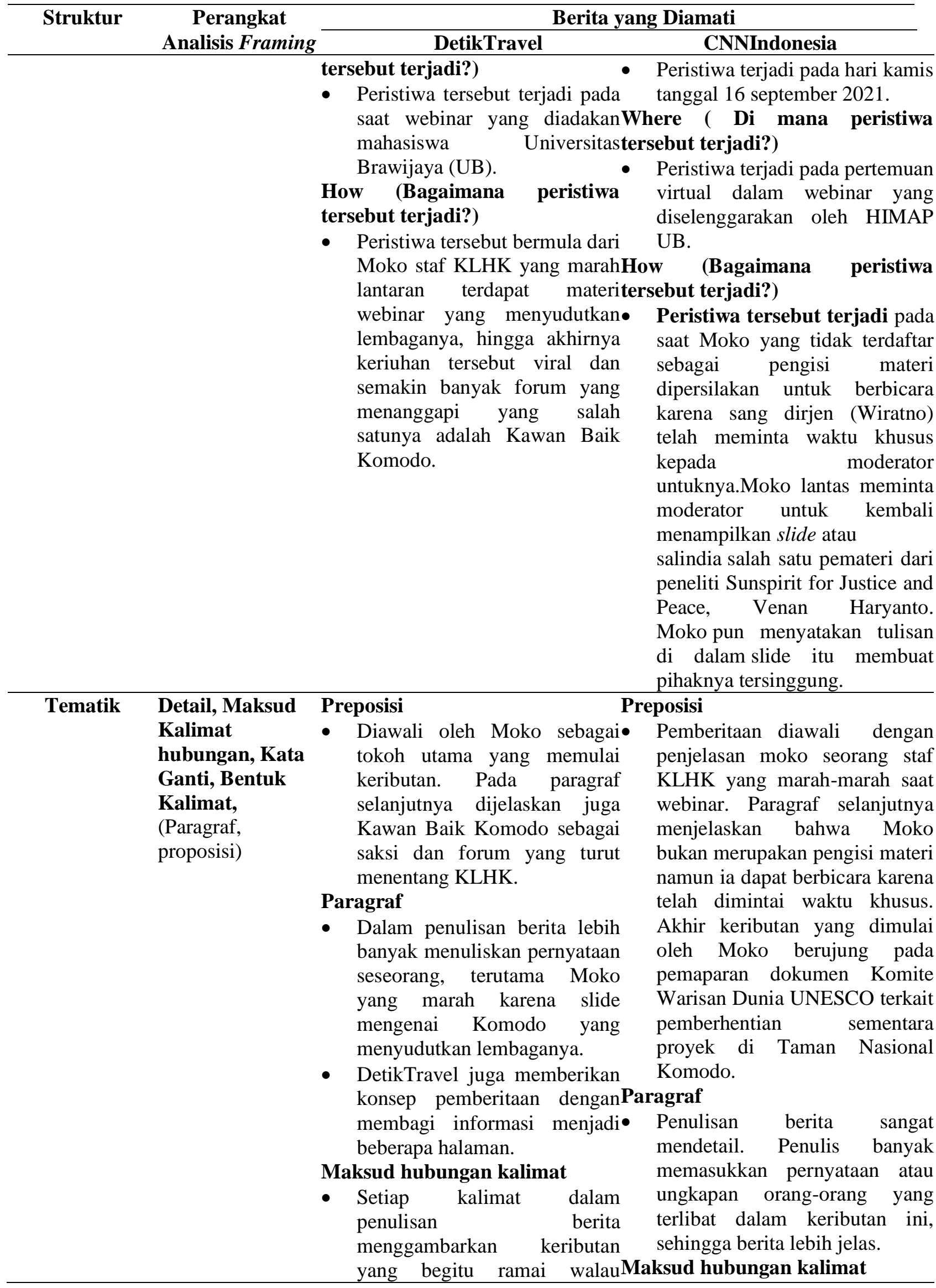



Ajar Teks Berita - Citra Retno Yulianti, Hendra Setiawan

DOI: https://doi.org/10.31004/edukatif.v4i1.1859

\begin{tabular}{|c|c|c|}
\hline Struktur & $\begin{array}{c}\text { Perangkat } \\
\text { Analisis Framing }\end{array}$ & Berita yar \\
\hline & & $\begin{array}{l}\text { hanya dalam webinar. Selain॰ } \\
\text { itu unggahan dari Kawan Baik } \\
\text { Komodo juga dihadirkan } \\
\text { sehingga lebih meyakinkan } \\
\text { bahwa KLHK adalah benar } \\
\text { penjahat lingkungan. }\end{array}$ \\
\hline
\end{tabular}

\section{Retoris dan Diksi \\ Leksikon, \\ Grafis, Metafora • Salah satu \\ (Kata, idiom, gambar/foto) \\ Diksi dan Idiom \\ Kementerian \\ Hidup dan Kehutanan (KLHK) seperti kebakaran jenggot. \\ (Kebakaran jenggot berarti \\ bingung atau marah tidak \\ karuan).}

- Awal mula percikan api• dimulai dari masyarakat sipil NTT yang mengungkit pemberian lahan sebagai kejahatan lingkungan. (Awal mula percikan api berarti awal mula masalah atau awal mula keributan).

- Staf KLHK yang berang dianggap penjahat. (Kata berang berarti sangat marah, sementara arti kata penjahat yaitu orang yang jahat seperti pencuri, perampok atau penodong).

- Ia marah-marah kala ada slide mengenai komodo yang menyudutkan lembaganya. (Kala berarti ketika sementara kata slide sama dengan salindia atau halaman tampilan dari power point)

\section{Gambar/Foto}

- Foto dokumentasi atau tangkapan layar saat acara webinar.

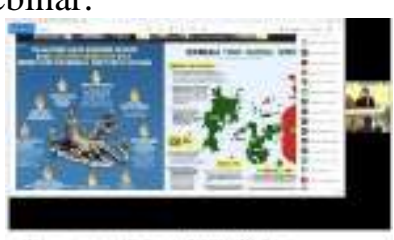

- Lampiran/tulisan unggahan Twitter Kawan Baik Komodo

\section{Diksi dann Idiom}

Pada penulisan berita ini, setiap kalimat saling berhubungan sebagai penjelas dan pendukung yang menggambarkan keributan pada saat weibar. Mulai dari pernyataan dan ugkapan orangorang yang terlibat hingga detail latar belakang orang tersebut.

- Moko sebagai staf Wiratno dipersilakan untuk berbicara karena sang dirjen yang meminta waktu khusus kepada moderator untuknya.

(Waktu khusus sama halnya dengan kesempatan)

Dengan nada tinggi lagi, Moko pun meminta kepada pemateri untuk membuat materi yang sopan dan tidak boleh menyinggung KLHK.

(Nada tinggi berarti sedang emosi atau sangat marah)

"Ya sebenarnya begini, mesti harus sabar [KLHK]. jadi UNESCO sudah keluarkan teguran, jadi sadarlah tidak usah merasa baper dengan kritik yang kita berikan, belajar dari itu, dan mari evaluasi total keseluruhan pembangunan yang ada di kawasan taman nasional," ujarnya saat dihubungi CNNIndonesia.com, Kamis (16/9).

(Baper sama artinya dengan bawa perasaan/marah).

- Wiratno pun mempertanyakan maksud dari slide itu dan bergantian mencak-mencak dengan Moko.

(Mencak-mencak sama halnya dengan marah atau ngamuk)

- Moko sewot atau marah-marah dalam webinar. (Sewot berarti marah atau jengkel).

- Mereka menilai slide itu berisi tuduhan bahwa KLHK telah melakukan kejahatan 
812 Analisis Framing dan Diksi Berita pada Media Online Detik Travel dan CNN Indonesia Sebagai Bahan Ajar Teks Berita - Citra Retno Yulianti, Hendra Setiawan

DOI: https://doi.org/10.31004/edukatif.v4i1.1859

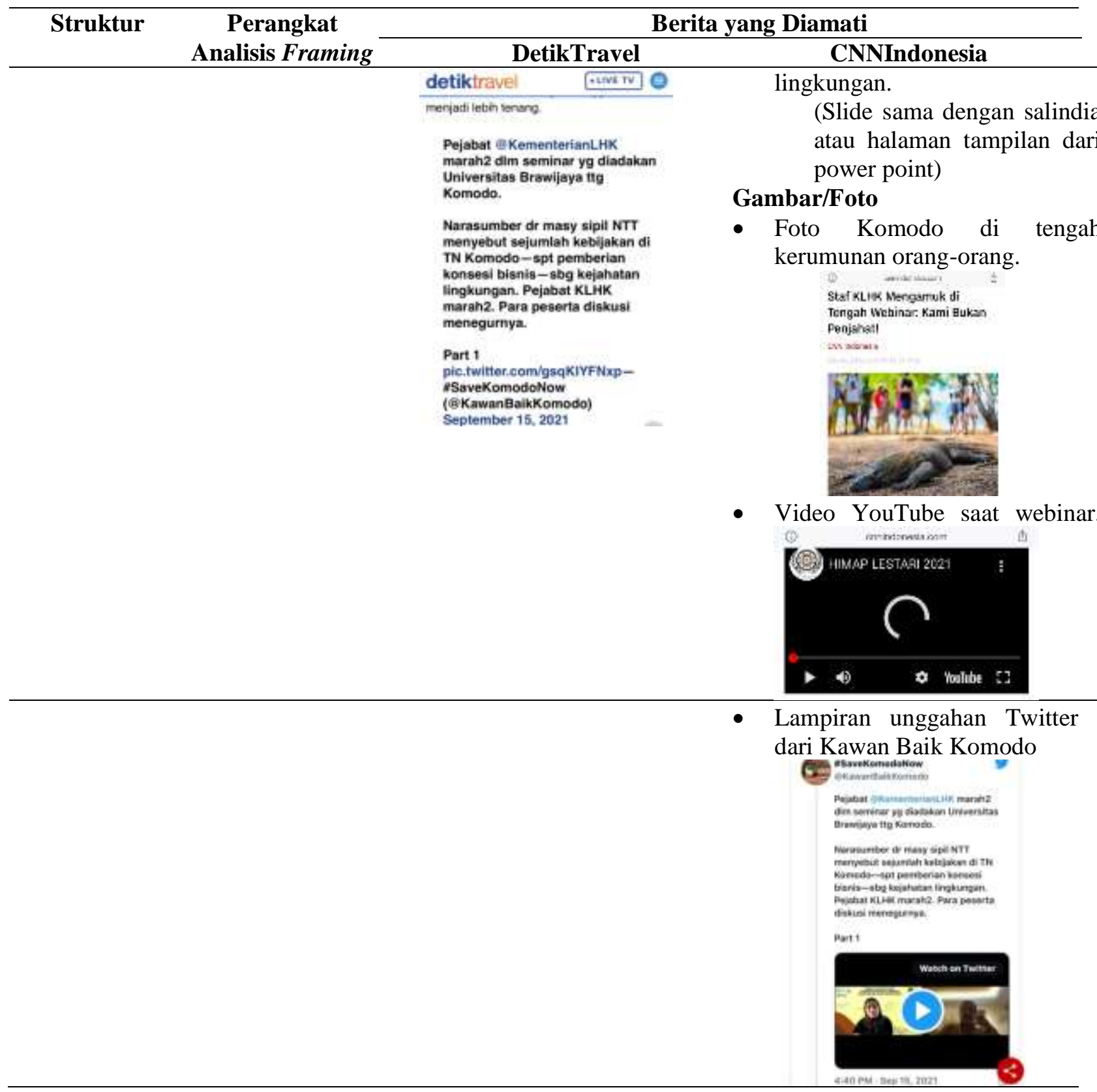

Berdasarkan skema analisis framing di atas keduanya memiliki pengemasan yang berbeda, mulai dari struktur skrip, tematik, sitaksis hingga pada struktur retorisnya. Sementara penggunaan diksi dalam penulisan berita, keduanya sama-sama memiliki diksi yang beragam dalam penyampaian beritanya. Adapun perbedaan yang paling menonjol terletak pada struktur tematik yaitu pada DetikTravel lebih menekankan pada alasan staf dari Kementerian Lingkungan Hidup dan Kehutanan (KLHK) marah saat webinar dan lebih banyak menuliskan ungkapan atau pernyataan orang-orang yang terlbiat. Sementara pada CNNIndonesia menyajikan data yang lebih lengkap dan akurat mulai dari kronologi keributan, menyebutkan detail orang-orang yang terlibat hingga pada latar belakang orang tersebut.

Adapun dalam konsep pemberitaan DetikTravel menyampaikan informasi dengan membaginya ke dalam beberapa halaman. Sementara CNNIndonesia langsung menginformasikan berita tersebut kedalam satu halaman. Sementara berdasarkan hasil analisis diketahui bahwa pemilihan kata (diksi) pada kedua teks berita dalam kasus ngamuknya staf KLHK saat webinar di situs media online DetikTravel dan CNN Indonesia edisi 
813 Analisis Framing dan Diksi Berita pada Media Online Detik Travel dan CNN Indonesia Sebagai Bahan Ajar Teks Berita - Citra Retno Yulianti, Hendra Setiawan

DOI: https://doi.org/10.31004/edukatif.v4i1.1859

16 September 2021, terdapat kata konkret, kata ilmiah dan kata asing. Selain itu, dalam pemberitaan CNNIndonesia terdapat penggunaan foto, tautan video YouTube serta Unggahan dari Kawan Baik Komodo yang lebih mendukung informasi berita.

Penggunaan foto yang dipilih pun sangat sesuai dengan isi berita yang berterkaitan dengan kerusakan ekosistem komodo oleh manusia. Sedangkan DetikTravel hanya melampirkan dokumentasi/tangkapan layar saat webinar berlangsung serta melampirkan tulisan dari unggahan Twitter Kawan Baik Komodo. Dalam hal ini, tentu pemberitaan CNNIndonesia lebih unggul karena dalam segala struktur, CNNIndonesia menuliskan berita secara detail dan melampirkan informasi-informasi pendukung informasi sehingga lebih memudahkan pembaca untuk menyimak informasi. Meskipun dalam pemilihan diksi keduanya memiliki diksi serta idiom yang bervariatif, dapat diketahui bahwa diksi serta idiom yang lebih menarik yaitu dalam berita DetikTravel.

\section{KESIMPULAN}

Dapat disimpulkan bahwa pada DetikTravel dan CNN Indonesia memiliki beberapa perbedaan dan persamaan dalam mengolah dan melakukan framing terhadap pemberitaannya. Terutama pada aspek sintaksis dan aspek skrip yang kedua media memiliki kesamaan. Namun untuk struktur retoris dan tematik CNN Indonesia jauh lebih detail dalam memberitakannya. Sedangkan dalam Detik.com lebih terpusat pada sebabakibat dari amarah staf KLHK. Hal menarik dalam kedua berita adalah terletak pada judul yang dimana CNN Indonesia menggunakan tanda baca perintah sementara pada DetikTravel Menggunakan tanda baca tanya. Tentu keduanya memiliki maksud dan tujuan yang berbeda dimana pada CNN Indonesia berarti menentang atau bentuk pembelaan diri, sedangkan pada DetikTravel berarti menanyakan kebenaran. Dalam pemilihan diksi pun sangat beragam, sehingga hasil dan pembahasan analisis ini sangat mungkin untuk digunakan dalam bahan ajar untuk teks berita.

\section{UCAPAN TERIMA KASIH}

Alhamdulillah, puji serta syukur saya panjatkan atas rahmat dan karunia Allah SWT. Karya ini penulis persembahkan kepada kedua orang tua, dosen pembimbing, sahabat-sahabat dan orang-orang yang telah membantu serta memberi semangat.

\section{DAFTAR PUSTAKA}

Eriyanto. (2011). Analisis Framing: Konstruksi, Ideologi, Dan Politik (N. H. Sa (Ed.)). Lkis: Yogyakarta.

Fadilah, U. N., Haris, A. M., \& Achmad, Z. A. (2020). Framing Media Online Cnnindonesia.Com Dan Detik.Com Mengenai Kebijakan Transisi Di Dki Jakarta. Jurnal Ilmu Komunikasi, 3(2), 1-17. Http://Jkom.Upnjatim.Ac.Id/Index.Php/Jkom/Article/View/92

Fajriyani, N., Ridho, M. R., \& Laili, Q. (2020). Analisis Kesalahan Berbahasa Di Bidang Diksi Dalam Buku Panduan Upt Perpustakaan Iain Surakarta Edisi 2018. Jurnal Penelitian Humaniora, 21(1), 55-68. Https://Doi.Org/10.23917/Humaniora.V21i1.8151

Harnia, N. T., Meliasanti, F., \& Setiawan, H. (2021). Analisis Framing Berita Perundungan Pada Media Online Detik.Com Dan Tribunnews.Com Sebagai Bahan Ajar Teks Berita Di Smp. Edukatif: Jurnal Ilmu Pendidikan, 3(5), 3145-3153. Https://Doi.Org/Https://Doi.Org/10.31004/Edukatif.V3i5.1240

Khoiri, A. M. (2021). Staf Klhk Ngamuk Di Webinar Komodo, Memangnya Kami Penjahat? Travel.Detik.Com. Https://Travel.Detik.Com/Travel-News/D-5726596/Staf-Klhk-Ngamuk-Di-WebinarKomodo-Memangnya-Kami-Penjahat/2. Diakses 30 Desember 2021.

Lingga, R. A. (2021). Staf Klhk Mengamuk Di Tengah Webinar: Kami Bukan Penjahat! Cnnindonesia.Com. 
814 Analisis Framing dan Diksi Berita pada Media Online Detik Travel dan CNN Indonesia Sebagai Bahan Ajar Teks Berita - Citra Retno Yulianti, Hendra Setiawan

DOI: https://doi.org/10.31004/edukatif.v4i1.1859

Https://Www.Cnnindonesia.Com/Nasional/20210916100814-20-695106/Staf-Klhk-Mengamuk-DiTengah-Webinar-Kami-Bukan-Penjahat. Diakses 30 Desember 2021.

Magdalena, I., Sundari, T., Nurkamilah, S., Nasrullah, \& Amalia, D. A. (2020). Analisis Bahan Ajar. Nusantara: Jurnal Pendidikan Dan Ilmu Sosial, 2(2), 311-326. Https://Ejournal.Stitpn.Ac.Id/Index.Php/Nusantara

Marzuki, A., \& Kahar. (2016). Analisis Framing Rubrik Laporan Utama Tabloid Verbeek. Jurnal Komunikasi Kareba, 5(2), 406-430. Http://Journal.Unhas.Ac.Id/Index.Php/Kareba/Article/Viewfile/1915/1073

Nilamsari, D., Ratnamulyani, I., \& Luthfie, M. (2016). Analisis Framing Pemberitaan Kota Bogor Di Media Online Www.Heibogor.Com Dan Www.Bogorplus.Com. Jurnal Komunikatio, 2(2), 107-113.

Prasetyo, N., Suciati, T. N., \& Sudarmanto, B. (2020). Framing Pemberitaan Sidang Gugatan Kasus Proyek Reklamasi Pantai Utara Jakarta. Jurnal Daring Mahasiswa Komunikasi, 1(1), 1-11.

Ramdoni, F., Meliasanti, F., \& Setiawan, H. (2021). Analisis Diksi Dan Gaya Bahasa Iklan Layanan Masyarakat Divisi Humas Polri Serta Relevansinya Sebagai Bahan Ajar Tingkat Smp. Edukatif: Jurnal Ilmu Pendidikan, 3(6), 3852-3865. Https://Doi.Org/Https://Doi.Org/10.31004/Edukatif.V3i6.1325

Romli, A. S. M., \& Kurniawan, I. (2012). Panduan Praktis Mengelola Media Online (I. Kurniawan (Ed.)). Nuansa Cendikia: Bandung.

Setiawan, H., \& Nulhakim, L. (2019). Analisis Framing Zong Dang Pan Dan Gerald M. Kosicki Pada Pemberitaan Kasus Dugaan Ujaran Kebencian Habib Bahar Bin Smith Kepada Presiden Joko Widodo (Studi Kasus Pada Kompas.Com Edisi 3 Desember 2018). Jurnal Artikula, 2(1), 48-53. Https://Doi.Org/10.30653/006.201921.19

Solihat, M., Setiawan, H., \& Meliasanti, F. (2021). Kajian Morfologis Pada Pemberitaan Habib Rizieq Shihab Rekomendasinya Sebagai Materi Menyusun Teks Berita Di Smp. Edukatif: Jurnal Ilmu Pendidikan, 3(6), 3828-3838. Https://Doi.Org/Https://Doi.Org/10.31004/Edukatif.V3i6.1259

Sugiyono, P. D. (2015). Metode Penelitian Pendidikan (Pendekatan Kuantitatif, Kualitatif, Dan R\&D) (2015 Ed.). Penerbit Alfabeta: Bandung.

Suprobo, T., Siahainenia, R., \& Sari, D. K. (2016). Analisis Framing Media Online Dalam Pemberitaan Profil Dan Kebijakan Menteri Susi Pudjiastuti (Studi Pada Situs Berita Detik.Com, Kompas.Com Dan Antaranews.Com Periode Oktober - Desember 2014). Cakrawala Jurnal Penelitian Sosial, 5(1), 119138. Http://Ejournal.Uksw.Edu/Cakrawala/Article/View/499

Suryawati, I. (2014). Jurnalistik Suatu Pengantar Teori Dan Praktik. Galia Indonesia: Bogor.

Tarigan, H. G. (2013). Menulis Sebagai Suatu Keterampilan Berbahasa. Penerbit Angkasa: Bandung.

Widarmanto, T. (2017). Pengantar Jurnalistik Panduan Awal Penulis Dan Jurnalis (A. Sasmita (Ed.)). Araska: Yogyakarta.

Wijaya, N. (2020). Mengenal Proyek "Jurassic Park" Di Ntt. Cnnindonesia.Com. Https://Www.Cnnindonesia.Com/Ekonomi/20201026142334-92-562801/Mengenal-Proyek-Jurassic-

Park-Di-

Ntt?Utm_Source=Twitter\&Utm_Medium=Oa\&Utm_Content=Cnnindonesia\&Utm_Campaign=Cmssoc med. Diakses 30 Desember 2021. 